\title{
Grau de Informação, Atitudes e Representações Sobre o Risco e a Prevenção de AIDS em Adolescentes Pobres do Rio de Janeiro, Brasil
}

\author{
Information, Attitudes, Perceptions, and Symbolic Representations of AIDS \\ Risk and Prevention Among Poor Adolescents in Rio de Janeiro, Brazil
}

\section{Edgar Merchán-Hamann}

\begin{abstract}
MERCHAN-HAMANN, E. Information, Attitudes, Perceptions, and Symbolic Representations of AIDS Risk and Prevention Among Poor Adolescents in Rio de Janeiro, Brazil. Cad. Saúde Públ., Rio de Janeiro, 11 (3): $463-479$ Jul/Sep, 1995.
\end{abstract}

Four hundred and sixteen poor adolescents of both sexes in Rio de Janeiro were interviewed to study both their level of information and symbolic representations concerning AIDS risk and prevention. The most common source of information on HIV/AIDS was the mass media, particularly television broadcasts. There were doubts and lack of trust regarding official government information on HIV/AIDS. Nearly $70 \%$ of the adolescents interviewed believe in HIV transmission through mosquito bites and some 40\% through casual contact with wounds or scars or sharing of bathroom utensils. Men seemed to show a greater awareness and autonomy vis-à-vis taking initiatives in sex encounters. Attitudes of segregation and exclusion of people with AIDS persist. Lack of prevention was attributed to the impossibility of predicting sexual encounters. The study of symbolic aspects concerning causes of HIVI AIDS displayed broad variability: $80 \%$ of the interviewees associated AIDS with excesses in sexual behavior and $40 \%$ with homosexual practices. Causal images vary from the predominant view of AIDS as unfair punishment to the less frequent stance considering AIDS as fair punishment (due to sinful behavior). An ambiguous attitude towards transgression (taking as its sterotype the figure of Rio's "malandro", or "streetwise dude") may influence perception of risk and prevention. The paper calls attention to the need for implementing clearer and more direct educational programs. This could be useful for the implementation of culturally sensitive control measures through a reshaping of AIDS symbols. The author recommends a better understanding of the social and economic determinants of disease and reinforcement of the kinds of discourse which empower and raise the self-esteem of poor adolescents by endorsing their civil rights.

Key words: AIDS; Adolescents; Attitudes; Perceptions

\section{INTRODUÇAO}

Este estudo visa contribuir para o conhecimento acerca da situação do adolescente brasileiro com respeito à Síndrome de Imunodeficiência Adquirida (AIDS) no seu meio. A experiência mundial de uma década e meia de história

\footnotetext{
${ }^{\prime}$ Programa de Doutorado, Escola Nacional de Saúde Pública. Rua Leopoldo Bulhões, 1480, 3andar, Rio de Janeiro, RJ, 21041-210, Brasil.
}

da AIDS tem ensinado que a prevenção bem-sucedida se baseia em três elementos: a) informação e educação; b) serviços de saúde e assistência social adequados às necessidades da comunidade que sofre as conseqüências da epidemia; c) apoio social. Desta tripla perspectiva, vinculam-se as dimensões individual, social e institucional/estatal da vulnerabilidade à AIDS (Mann et al., 1993). Até 1992, as políticas do governo brasileiro para a prevenção da AIDS não tinham conseguido implementar programas 
básicos de prevenção e assistência que demonstrassem um impacto significativo frente à crise gerada pela epidemia de AIDS, mostrando, ao contrário, uma determinação política hesitante (Parker, 1994). Aparentemente, o papel de setores da sociedade civil organizada, em particular o das organizações não governamentais, tem sido fundamental não só no que diz respeito à prevenção da infecção, mas também no que tange à garantia dos direitos de cidadania e a reivindicação de assistência básica e tratamento às pessoas vivendo com AIDS (Vallinoto, 1991; Parker, 1994). H5 consenso mundial quanto à importância decisiva de se implementarem programas de prevenção para jovens, antes que estes iniciem práticas comportamentais que possam aumentar o risco de transmissão do vírus da imunodeficiência humana (HIV). O trabalho preventivo com jovens faz-se importante, à medida que vários estudos evidenciaram o aparecimento de soropositividade para o HIV já na adolescência (Miller et al., 1990). No Brasil, informações e trabalhos práticos com adolescentes ainda são escassos. Com o intuito de fornecer novas propostas de prevenção adequadas ao cotidiano do adolescente, Paiva (1994) tem trabalhado sobre este tema no âmbito de uma escola noturna de uma área pobre de São Paulo. Para esta autora, há uma influência importante da construção cultural do gênero e da sexualidade nas decisões que se tomam com respeito à conduta sexual. Estes aspectos da realidade são geralmente esquecidos nos estudos sobre a AIDS e o seu desconhecimento induz a concepções de autonomia e responsabilidade que estão fora do contexto específico do cotidiano do adolescente.

O objetivo último desta pesquisa é permitir a implementação de ações de prevenção mais próximas da realidade do adolescente, traduzidas em práticas de educação em saúde orientadas para a profilaxia da AIDS, que levem em conta os contextos social e cultural em que o risco ocorre no cotidiano de adolescentes pobres do Rio de Janeiro.

\section{POPULAÇÃO ESTUDADA E MÉTODOS}

As informações aqui registradas fazem parte de uma pesquisa efetuada durante 1991 com uma população de adolescentes no Centro Brasileiro para a Infância e Adolescência (CBIA), conhecido anteriormente como Fundação Nacional de Bem-Estar do Menor (Funabem), órgão federal de assistência ao menor, vinculado ao Ministério da Ação Social. Os locais onde foi desenvolvido o trabalho eram de dois tipos: escolas abertas à comunidade e escolas fechadas em regime de internato carcerário para adolescentes infratores.

A clientela das escolas abertas era composta de alunos provenientes das favelas e bairros pobres das zonas norte e oeste do Rio de Janeiro e municípios da Baixada Fluminense. Nestas instituições era oferecida a educação formal cur-

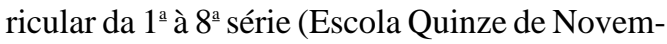
bro, no Bairro Quintino Boacaiúva), ou alfabetização e cursos profissionalizantes (Escola Stella Maris, na Ilha do Governador). O segundo tipo corresponde a escolas fechadas em regime carcerário para adolescentes infratores (Centro de Recepção e Triagem do Complexo de Quintino e Escola João Luiz Alves, na Ilha do Governador). Nas escolas fechadas os internos são procedentes, na maioria dos casos, da Baixada Fluminense e da zona Norte da região metropolitana. Há também uma minoria oriunda de municípios do interior do Estado do Rio de Janeiro.

Cerca de um terço dos alunos entrevistados declarou exercer algum tipo de trabalho. A maioria dependia economicamente, pelo menos em parte, de um pai ou outro responsável que trabalhava (75\%). Tratava-se de pessoas engajadas no setor de serviços, executando trabalho não qualificado ou semi-qualificado (61\%). Muitas encontravam-se formalmente empregados, representando um pouco mais de um terço do total, enquanto outros desempenhavam atividades variadas como autônomos (27\%). O restante dos pais fazia parte de setores informais da economia $(6,5 \%)$, ou recebia pensão ou aposentadoria (7\%). Embóra somente $2 \%$ tenham-se declarado desempregados, fica difícil delimitar a linha entre desemprego e emprego, já que a condição de empregado amiúde era substituída pela de subemprego dentro da economia informal. Dentre as mães, $66 \%$ exerciam ocupações com graus diversos de especialização, sendo mais comuns os ofícios domésticos (35\%). Outras desempenhavam ofícios semi-qualificados com emprego fixo $(18 \%)$. A condição de "dona de casa" como 
única ocupação foi assinalada em $25 \%$ dos casos e a dependência de pensões e aposentadorias cobria cerca de $8 \%$. Cerca de $25 \%$ dos entrevistados não mora com os dois pais biológicos. O número médio de irmãos está entre $3 \mathrm{e}$ 4. Um terço dos mesmos tinha antecedente de institucionalização e cerca de $10 \%$ tinham morado na rua.

Durante seis meses foram realizadas uma ou mais entrevistas utilizando-se um questionário fechado para avaliação de atitudes, percepções e práticas. Além das respostas a perguntas específicas, foram registradas por meio de entrevistas abertas, as apreciações subjetivas e comentários sobre a AIDS e os riscos a ela vinculados. As entrevistas foram voluntárias, anônimas, individuais e confidenciais. Os estudantes foram informados sobre o seu direito de não responder perguntas, assim como sobre o uso das informações coletadas. Depois das entrevistas, eram realizadas oficinas encorajando os alunos a levantarem dúvidas com respeito à transmissão da AIDS e ao uso do preservativo. Também foram registrados em forma aberta outros fatos relacionados com o objeto desta pesquisa, como conversas informais com professores, monitores, psicólogos, assistentes sociais e médicos das escolas.

Foram entrevistados 416 alunos entre 13-18 anos de idade, dos quais 353 (85\%) estudavam em escolas abertas e 63 (15\%) estavam internados em instituições fechadas; 325 do total (78\%) eram de sexo masculino e 91 (22\%) de sexo feminino. Quase $70 \%$ dos alunos tinham cursado até a $5^{\mathrm{a}}$ série; os restantes estavam entre a $5^{\mathrm{a}}$ e a $8^{\mathrm{a}}$ séries. Em média os alunos haviam sido reprovados em duas séries.

\section{RESULTADOS}

\section{As Fontes de Informação}

Todos os entrevistados tinham ouvido falar em AIDS. Os principais veículos de conhecimento foram a televisão e o rádio, que davam conta de $65 \%$ das fontes primárias de informação. A obtenção de informação mediante conversas informais com amigos e colegas foi mencionada por $13 \%$ dos entrevistados como fonte primária de conhecimento sobre AIDS, seguida da exposição a material veiculado por instituições de saúde $(10 \%)$ e pelos professores da escola $(7,8 \%)$. Foi de pouca relevância a leitura de material impresso, cartazes, revistas, jornais e as conversas com parentes. A televisão e o rádio responderam por mais de $40 \%$ das fontes secundárias de informação, seguida da conversa informal com amigos (20\%). Deve-se ressaltar que, no semestre anterior à pesquisa, havia sido exibido um vídeo sobre a AIDS e realizada uma reunião com a participação de professores de uma das escolas e de médicos do Hospital da Criança, pertencente à CBIA. As escolas não contavam com um programa regular e permanente de veiculação de material educativo sobre a AIDS. Uma minoria mencionou os professores como fonte de conhecimento sobre o tema.

Foi observado que o conhecimento e a preocupação acerca da AIDS aumentavam quando os adolescentes conheciam alguém com a doença. Este fato foi referido por um terço dos entrevistados, principalmente em uma das escolas abertas, onde houve três alunos que sofreram da doença durante o ano de 1990.

\section{Percepção de Risco e Contágio}

A noção de contágio existia e se constituía em fonte de preocupação, sobretudo na eventualidade do início da atividade sexual. Por ocasião das entrevistas, mais da metade dos adolescentes de ambos os sexos já haviam tido relações sexuais. A maioria dos entrevistados de sexo masculino tinha refletido a respeito da AIDS e sabia que era um evento real com o qual tinha que se lidar. A idéia de contágio estava muito bem definida nas suas falas. Entre os alunos mais velhos houve consenso quase total de que sua atividade sexual tinha mudado desde o aparecimento da AIDS:

\section{"Agora não dá para ir à toa por aí, transando com qualquer garota...". (Informante 04-321, sexo M, 18 anos)}

Havia entre eles preocupação com a AIDS, existindo a crença em múltiplas formas de contágio além do contato de fluidos corporais via relação sexual ou injeção. Eis aqui um resumo das respostas positivas para modos de transmissão: por picada de mosquito (68\%); encostar em fe- 
ridas ou contato da pele com secreções (43\%n); sentar no vaso sanitário (40\%); beber do mesmo copo de uma pessoa infectada (35\%); por tosse ou espirro de pessoa infectada (21\%); pegar as mãos $(6 \%)$. Mais de um terço dos alunos $(36 \%)$ achou que as pessoas infectadas deveriam ser afastadas do convívio na escola ou no trabalho, para evitar o contágio de outros colegas.

Em alguns casos, houve uma compreensão diferente do material veiculado nos meios de massa: $57 \%$ dos entrevistados acharam que os usuários de drogas endovenosas sempre pegavam AIDS e $20 \%$ pensaram que doer sangue podia levar ao contágio. Houve confusão com outras doenças epidêmicas como cólera e dengue, e depoimentos que mostraram ambigüidade e sensacionalismo:

"Na televisão disseram que dentista dá AIDS”. (Informante 01-204, M, 16 anos)

Ademais, foi notória a desconfiança da veracidade do conteúdo do material veiculado. Escutou-se com frequiência que o número de pessoas com AIDS deve ser muito superior ao oficialmente divulgado:

"Eles escondem o jogo".

(Informante 01-061, F, 13 anos)

Numa análise das respostas a dezesseis perguntas relacionadas com conhecimento da AIDS, constatou-se que em 9 delas havia discrepâncias entre homens e mulheres: as entrevistadas responderam "não sei” entre 2 a 7 vezes mais freqüentemente do que adolescentes de sexo masculino. Em 5 destas perguntas sobre contágio e formas de prevenção, as mulheres falharam mais do que os homens, e uma grande proporção delas achou que há uma vacina protetora contra AIDS, que se pode contrair AIDS sentando no local onde se sentou uma pessoa com AIDS, por uso de qualquer droga, ou doando sangue. Também foi mais freqüente entre elas a idéia de poder-se evitar o contágio lavando bem as mãos ou com asseio vaginal. Em contraste, as respostas a três perguntas mostraram uma proporção maior de erros por parte dos homens, que consideraram com maior freqüência que o mosquito transmite o HIV, embora esta diferença se torne mais tênue dada a alta proporção de incerteza das mulheres. Eles também acharam que o sexo heterossexual, incluindo o sexo anal entre indivíduos casados, não oferece riscos ao contágio. A AIDS foi vista pelas entrevistadas como uma questão mais distante e, embora o nível de conhecimento seja aparentemente menor nelas, tomou-se evidente que os entrevistados tendem a dar respostas categóricas (sim ou não) mais freqüentemente e com maior certeza do que as primeiras. As fontes de conhecimento da AIDS foram similares nos dois sexos, sendo apenas mais freqüente entre as alunas a leitura de revistas dirigidas ao público feminino que, amiúde, trazem o tema à tona.

Entre as entrevistadas, a pressão da família e as restrições se encontravam entre suas preocupações mais prementes, parecendo ser estas mais importantes do que os riscos de contrair doença. A atividade sexual, ou mesmo os relacionamentos íntimos, assumiam uma condição quase clandestina:

"A minha mãe prende a gente". (Informante 01-122, F, 17 anos)

\section{"Se meu pai fica sabendo que eu estou namorando, ele me mata". (Informante 01-151, F, 14 anos)}

A noção de risco, entendido como o perigo e não necessariamente como a probabilidade (as chances) de "contaminação", esteve também presente nos dois sexos. A maioria dos estudantes de sexo masculino percebia que existia o "risco" de contágio. Entre eles, as razões mencionadas para não usar qualquer tipo de proteção durante o ato sexual, além da falta de conhecimento sobre a AIDS, estiveram ligadas primordialmente à impossibilidade de prever que isso ia ocorrer, o que aconteceu também nas relações homossexuais:

“... você sabe, nessa hora não dá para segurar”. (Informante 01-043, M, 18 anos)

“... a mina deu mole... O que eu ia fazer? ... se eu ia comprar perdia minha vez”. (Informante 01-292, M, 16 anos) 
Uma outra razão para não ter tido nenhum tipo de proteção foi o fato de confiar na parceira. A maioria dos alunos conhecia, ou tinha escutado falar dos preservativos de borracha e sabiam da sua utilidade para se prevenir da AIDS. Houve inclusive casos em que não sabiam que eles também servem para a prevenção da gravidez. A despeito deste conhecimento sobre a "camisinha", somente três alunos as levavam consigo no momento da entrevista. Houve também grande desconhecimento a respeito dos locais de venda e preços, isto é, da disponibilidade prática delas:

\section{"Na hora eu não tinha. Nunca comprei...". (Informante 01-173, M, 17 anos)}

A maioria dos entrevistados de sexo masculino acha que é possível saber pela aparência física quando uma pessoa está com AIDS e que isso pode ser importante como prevenção do contágio. Também é importante a percepção da "índole" da parceira, baseada na aparência:

"Eu vejo que a mina seja limpa, que não tenha caroços na pele, que não tenha manchas... “. (Informante 01-382, M, 17 anos)

"Dá para saber quando ela é direita; só pelo jeito”. (Informante 04-404, M, 15 anos)

Em geral, foi mais fácil para os entrevistados dos dois sexos perceberem a possibilidade de contágio em outras pessoas do que se verem "em risco" eles próprios. Quase $80 \%$ dos adolescentes responderam que a "promiscuidade" é a causa da epidemia de AIDS e 27\% acharam que somente pega AIDS quem tem muita atividade sexual, bastando isto para não se preocuparem.

Os estudantes de sexo masculino manifestaram-se aparentemente mais autônomos nas suas decisões com respeito à iniciativa sexual, isto é, eles decidiram porque acharam que aquela era a pessoa certa. Dependeram, portanto, unicamente da aquiescência da parceira. Houve, porérn, casos pouco freqüentes de pressão social por parte de pares ou de parentes próximos com precedência de poder sobre eles, resultando em coação:
"Os garotos iam ficar me zoando". (Informante 01-171, M, 15 anos)

Entre as alunas, com algumas exceções, a possibilidade de contágio foi vista como mais remota e muitas vezes não era sequer cogitada. Em geral percebida como um risco de outras pessoas:

“É ruim d'eu pegar uma doença dessas. Isso só dá em 'viado' e em menina vadia". (Informante 02-220, F, 13 anos)

\section{"Só as garotas de baile devem tomar cuidado”. (Informante 01-121, F, 17 anos)}

Ao contrário dos alunos, a aparência do parceiro não foi um critério para as entrevista das tomarem precauções, na eventualidade do ato sexual. A maioria das alunas baseou sua decisão nas "intenções" do parceiro e, secundariamente, no seu “ jeito" ou "índole". Não houve menção ao aspecto físico do companheiro. Foi também constatado que as alunas não pareciam possuir o mesmo grau de autonomia no relacionamento. Assim, tanto no fato de participar ou não de eventos sociais, como na atividade sexual ou no uso de qualquer tipo de prevenção, os adolescentes de sexo masculino se mostraram mais dispostos a declarar que a sua vontade predominava sobre a das mulheres. Isto não significa que não tenha existido consentimento por parte delas com respeito ao ato sexual. Foi notável que muitas tenham colocado a responsabilidade das preocupações com a AIDS, no parceiro, quando perguntadas se levariam consigo camisinhas:

\section{"É o rapaz que tem que se preocupar. A gente não vai usar camisinha, são eles”. (Informante 01-069, F, 16 anos)}

"Se a gente levar camisinha eles vão pensar que a gente está se oferecendo".

(Informante 02-241, F, 15 anos)

"Se a menina pedir para ele usar camisinha, com certeza ele vai ficar zangado". (Informante 02-213, F, 15 anos) 
Em nenhum caso as entrevistadas tinham consigo preservativos. Só excepcionalmente elas manifestaram que, de alguma maneira, parte da responsabilidade e da iniciativa poderia partir delas. Foi revelador o fato de que algumas alunas que praticam ou praticaram prostituição conheciam muito mais sobre a prevenção da AIDS e sua forma de transmissão do que as outras estudantes. Elas tinham utilizado preservativos com seus parceiros, particularmente durante o contato com estrangeiros. Este fato, porém, foi pouco freqüente:

\section{"Hoje em dia isso é normal. A mulher tem que se cuidar”. (Informante 01-034, F, 15 anos)}

A precedência do parceiro na imposição da sua vontade foi vista também em relação a outras conseqüências da atividade sexual. A gravidez não desejada, por exemplo, ocorreu em quatro adolescentes durante os 6 meses da pesquisa. A anticoncepção era praticamente desconhecida, particularmente pelas entrevistadas com menos experiência:

"Eu não sei como até agora não engravidei.

Nunca usei nada para evitar ".

(Informante 01-399, sexo F, 14 anos)

\section{Representações Sobre as Causas da Epidemia}

Quanto à percepção sobre as causas da existência da doença no Brasil, na maioria dos casos, aceitou-se como algo natural. Inicialmente não houve atribuição de culpa ou de responsabilidade a outrem pela entrada da AIDS no Brasil.

\section{"É uma doença como outra qualquer ... eu não acho que ninguém seja culpado". (Informante 02-229, F, 16 anos)}

Porém, cerca de $80 \%$ dos entrevistados atribuíram a epidemia ao "excesso" de atividade sexual. Em quase $40 \%$ das entrevistas assinalou-se a atividade homossexual como responsável pelo aparecimento e disseminação da AIDS, sendo esta resposta mais freqüente entre homens do que em mulheres, como neste depoimento de um ex-menino de rua:
"Eu não como viado porque dá AIDS na certa. Eles estão cheios de AIDS". (Informante 04-306, M, 17 anos)

Em uma quinta parte das entrevistas se culpabilizou os estrangeiros e seus costumes, sendo mencionados eventos recentes em que a afluência internacional foi grande (e.g., Rock in Rio II e carnaval). Houve a percepção de uma associação temporal destes eventos com o aparecimento de pessoas com AIDS:

... depois de Rock in Rio foi que começaram a aparecer pessoas com AIDS, como Cazuza... “. (Informante 04-347, M, 17 anos)

Em 18\% das entrevistas, a AIDS foi vista como um castigo justo por excessos e pecados. Em $12 \%$, foi atribuído o contágio ao azar. Foi raro escutar que a AIDS seja uma invenção, algo que não existe, embora este caso se tenha dado como também a percepção da AIDS como uma criação de laboratório, ou algo deliberadamente introduzido no país. Em um caso, uma suposta "culpa" pela introdução ou pela presença da doença no país foi dirigida aos próprios brasileiros:

“... os culpados somos nós, que transamos com eles”. (Informante 01-027, M, 18 anos)

\section{A AIDS e a Sujeira no Corpo}

A primeira representação que surge no discurso dos adolescentes sobre a doença é a caracterização dicotômica das pessoas em sujas e limpas. A integridade do corpo físico se valoriza e se identifica com "limpeza". Fica evidente, por outra parte, a identificação da AIDS com o deterioramento físico lento e irremediável: a queda de cabelo e a magreza foram identificados como fatos mais temidos. A palavra "manchas" foi mencionada com maior freqüência do que outros termos para designar tipos diferentes de lesões de pele, como "feridas", "caroços".

\section{AIDS e Usurpação do Corpo}

A visão da doença como um fato natural em que ,as vítimas não eram responsabilizadas foi predominante entre os entrevistados de ambos 
os sexos. Foram comuns as representações da morte ou da usurpação do corpo como algo totalmente fora do controle humano. A este respeito, apesar da escassa frequiência com que os entrevistados identificaram a AIDS como criação deliberada em laboratório, os entrevistadores foram inquiridos várias vezes sobre esta possibilidade quando chamados a responder dúvidas. A forma mais elaborada de representação da AIDS foi a informação que circulou na Escola Quinze de Novembro de que uma mulher seduzia rapazes e depois de manter relações sexuais com eles em motéis, fugia deixando escrito com baton no espelho do banheiro "agora você também está com a AIDS". Também se escutou que em alguns centros comerciais vários homossexuais tinham entrado no supermercado ameaçando as pessoas de infectá-las, cortando-se e "espirrando" sangue sobre elas. Estas versões foram escutadas várias vezes e nunca confirmadas.

Cerca de $20 \%$ dos entrevistados identificaram a AIDS como castigo justificado por pecados ou faltas. Nos restantes depoimentos há mais confusão do que consenso. Em ocasiões, o fato de andar com pessoas "suspeitas" ou "erradas" foi visto como justificativa de punição.

\section{AIDS, o Corpo e a Morte}

Além da usurpação ou domínio do corpo, a imagem da deterioração do mesmo, da morte lenta, foi a que encerrou maior dificuldade de ser abordada e enfrentada pelos adolescentes a respeito da AIDS. Os entrevistados que conheceram os estudantes que haviam morrido da doença no ano anterior à entrevista, descreveram as mudanças corporais dos seus amigos, particularmente as "manchas" e a queda do cabelo. Foi notório que os adolescentes infratores manifestassem com freqüência, que se eles tivessem AIDS, matariam "uns quantos", e depois se suicidariam:

"Se eu tenho AIDS eu não vou só. Eu saio, cheiradão, e mato uns quantos PM's, civis, $e$ depois me mato. Eu vou morrer mesmo..." (Informante 04-329, M, 16 anos)

(Nota do Autor: "PM" = policial militar; "civis" = policial civil)

\section{AIDS e Iniciação Sexual}

A necessidade de ter iniciação sexual foi encarada com naturalidade e em poucos casos houve um grau de preocupação com o fato de a AIDS levar ao adiamento deste evento. A religiosidade também não foi colocada como um fator que impedisse a determinação de iniciar a vida sexual, isto é, em nenhum caso a crença religiosa apareceu como determinante de coerção ou abstinência sexual. Também não existiu uma necessidade iminente de estabelecer o relacionamento sob a instituição do casamento.

\section{AIDS, Sexualidade e os Comportamentos}

A noção de diferença, marginalidade e a aproximação a ela com graus diversos de tolerância, esteve presente no discurso dos adolescentes em forma aparentemente contraditória. Se por um lado, havia um fascínio, uma curiosidade que levava à aproximação, existia por outro lado, a rejeição em público de manifestações tidas como desviantes. Algumas vezes, esta rejeição se relacionava com a AIDS. As aproximações à divergência revelam-se no ambiente de segredo da vida íntima ou, no ambiente público, nas piadas e comentários que ridicularizavam práticas como o homossexualismo ou o uso de drogas, sempre referidas a outras pessoas:

\section{"Ele é chegado nos rapazes...". \\ (Informante 01-093, sexo F, 18 anos)}

Tratando-se de relações homoeróticas, a própria caracterização da atividade sexual mudava. A masturbação a dois ou em grupo, por exemplo, não foi considerada atividade sexual. Outras vezes não foi tão fácil a percepção de um ato homossexual ou de uma manifestação de homoerotismo quando o entrevistado era "ativo":

\section{... Se eu tive sexo com outro homem? Não, sexo não, só brincadeira". \\ (Informante 04-341, M, 16 anos)}

"Sim, eu já comi viado".

(Informante 01-191, M, 16 anos) 
"Só boquete, mas foi a bicha que chupou". (Informante 03-305, M, 17 anos) (Nota do Autor: "boquete" = sexo oral)

As perguntas referentes à atividade homoerótica nem sempre foram encaradas como "brincadeira" nem como uma possibilidade entre outras. Em alguns entrevistados causaram preocupação e ansiedade. Houve algumas manifestações de rejeição total das práticas consideradas "anti-naturais":

"Eu nasci homem e homem vou morrer". (Informante 01-016, M, 15 anos)

"Eu sou mulher e não preciso procurar outra mulher. Para que, se a mulher tem o mesmo que eu tenho”. (Informante 01-093, F, 18 anos)

Em outros depoimentos as práticas homossexuais foram vistas como parte da natureza de algumas pessoas:

"Eu sou bicha, não tem jeito, Deus me fez. assim”. (Informante 01-277, M, 16 anos)

Em muitos casos, os entrevistados achavam que não estavam em risco de pegar AIDS pelo fato de não terem desempenhado um papel "passivo" na relação. Um deles perguntou:

\section{"Quem dá é quem pega, não é?" (Informante 04-320, M, 17 anos)}

$\mathrm{Na}$ perspectiva dos adolescentes entrevistados, oriundos de favelas dos morros, a transgressão era vista como "coisa de malandro". A definição de malandragem e o posicionamento a seu respeito nem sempre foram claros ou precisos. As atitudes para a figura do "malandro" mostraram, na maioria dos casos, uma posição de ambivalência. De um lado, houve depoimentos que relatavam com orgulho episódios de malandragem, ou da vida passada de "bandidos". De outro lado, expressava-se rejeição à malandragem:

"Hoje em dia o maior otário é o malandro, porque ele sempre se dá mal". (Informante 01-173, M, 17 anos)
"Eu não gosto desses garotos que vêm cheios de marra". (Informante 01-147, M, 18 anos)

“... eu já fui malandro, mas essa vida não presta. Olha só, estou aqui, preso”.

(Informante 03-305, M, 17 anos)

Foi interessante o fato de associar a figura do malandro na comunidade como uma pessoa muito ativa do ponto de vista sexual. Esta imagem se aproximava à alusão freqüente ao "garanhão" e contrasta com outras imagens como a do "otário" ou "corno":

“Esse aî não come ninguém. É um otário”. (Informante 02-225, M, 15 anos)

Alguns moradores de favela manifestaram que a experiência ("a esperteza") do malandro lhe permitia reconhecer mais facilmente se alguém está com AIDS. Amiúde também escutou-se falar de forma pejorativa de alguma outra pessoa utilizando seu desempenho sexual. Eis aqui alguns exemplos destas situações:

"Bandido só pega AIDS na cadeia porque aqui fora todo o mundo sabe quem é quem" (Informante 01-102, M, 16 anos)

"Otário pega AIDS porque não sabe bem o negócio, pega qualquer mulher..."

(Informante 04-307, M, 18 anos)

\section{A Visão dos Professores e Monitores}

O convívio com professores e monitores durante a pesquisa demonstrou uma vontade de colaboração e apoio irrestrito às atividades de pesquisa e educação em saúde. Embora seus pontos de vista não tenham sido registrados sistematicamente, eles foram anotados durante reuniões prévias ao desenvolvimento da pesquisa, assim como em discussões e oficinas das quais eles participaram ao longo do trabalho. Muitos professores manifestaram não só dúvidas, mas também insegurança para enfrentar perguntas dos alunos com respeito a temas considerados delicados. O teor das dúvidas sobre AIDS e infecção pelo HIV foi muito similar ao dos alunos. 
Em uma ocasião, um monitor da escola de infratores impediu um grupo de alunos de sentar-se nas cadeiras utilizadas pelos guardas e monitores sob a alegação de os menores terem doenças que "podem transmitir para a gente". Os alunos recebiam destas pessoas mensagens por vezes inconsistentes. Nas escolas abertas houve manifestações de carinho. Por outra parte, foi comum referirem-se aos alunos com atitudes de compaixão ou lástima, como "coitados" ou utilizando categorias de patologia, o que torna mais difícil o ensino:

\section{"Eles têm muito comprometimento". (Professora de $1^{\circ} \mathrm{Grau}$ )}

\section{DISCUSSÃO}

Ficou claro que a obtenção de informações sobre a AIDS/HIV sofre influência dos meios de comunicação de massa, particularmente a televisão. No entanto, apesar de não ter sido feita uma pesquisa a fim de correlacionar o grau de audiência e a qualidade do conhecimento, a apuração das respostas a perguntas sobre a AIDS revela dúvidas importantes a respeito da forma de transmissão da infecção, obrigando a questionar o impacto das campanhas veiculadas até o momento da realização da pesquisa. É provável que as percepções sobre a AIDS, como uma doença transmitida de várias maneiras, retratem e ultrapassem, em muitos casos, a ambigüidade das mensagens veiculadas pelos meios citados.

$\mathrm{Na}$ época em que se realizou a pesquisa, uma propaganda do Ministério da Saúde era televisionada e reproduzida em cartazes que estampavam a mensagem: "Se você não se cuidar, a AIDS vai to pegar". A AIDS era representada como uma figura mascarada, um "fantasminha". As pessoas eram silhuetas anônimas com alvos localizados sobre as áreas genitais. Este tipo de representação misteriosa da transmissão pode explicar, em parte, as concepções preconceituosas identificadas no discurso dos adolescentes, assim como algumas percepções sobre as causas da epidemia e as formas de contágio. É necessário ressaltar que este não é um fenômeno exclusivo do Brasil. Na França, onde inquéritos repetidos têm demonstrado uma melhora no nível de conhecimento sobre a transmissão e prevenção, e ainda, mudanças nas práticas, podemos observar a persistência de graus diversos de dificuldade na identificação correta dos mecanismos de infecção (Pollak et al., 1989). Um melhor conhecimento leva também a atitudes mais tolerantes e a uma diminuição na sensação de "temor pela doença" (Moatti et al., 1992), o que pode ser o resultado do impacto de intervenções significativas implementadas desde meados da década de 80 e acompanhadas por um grupo interdisciplinar.

Pode-se explicar a situação verificada na pesquisa como decorrência da inadequação do material veiculado em termos de clareza, quando dirigido ao público adolescente com este nível de escolaridade. Também pode colaborar com esta situação a falta de coerência das políticas públicas sobre a AIDS (Parker, 1994), aliada à falta de continuidade das campanhas. Um reflexo disto pode ser a persistência de atitudes de segregação como se viu na afirmação de que era necessário afastar as pessoas infectadas do trabalho e da escola, presente em mais de um terço dos entrevistados. Deve-se recordar que não havia nas escolas um programa regular de educação sexual e que muitos professores manifestaram dificuldade na abordagem de temas relacionados à AIDS. Destaca-se o fato de que o grau de conhecimento sobre a doença/infecção e a prevenção aumentou somente em situações particulares. A este respeito, DiClemente et al. (1987), trabalhando com adolescentes em São Francisco, Califórnia, assinalaram a proximidade geográfica com os "epicentros" da epidemia como um fator que aumenta a probabilidade de conhecimento a respeito de estratégias de redução do risco e o nível de preocupação dos adolescentes para com a AIDS.

Além de eventuais intervenções dos programas ministeriais e das organizações não governamentais, a televisão brasileira reproduz informações jornalísticas estrangeiras, cujos conteúdos reproduzem e recriam uma estrutura de pensamento em que a doença passa a revestir as atribuições de uma construção cultural. Vários pesquisadores têm investigado o papel de alguns meios de comunicação em termos de criar uma "opinião pública" sobre a AIDS, baseada 
em um senso comum precário (Watney, 1989; Pollak, 1990; Patton, 1990; Treichler, 1991; Herzlich \& Pierret, 1992). Dentre as muitas implicações das representações por eles veiculadas podemos destacar, em primeiro lugar, que os seus conteúdos não estão isentos da influência de relações específicas de poder (em nível micro ou macro) e constituem ideologia assim como o próprio discurso biológico e médico lhes proporciona suporte conceitual. Em segundo lugar, criou-se um senso comum decorrente da visão epidemiológica referente à AIDS e outros problemas de saúde, baseada numa concepção particular do conceito de risco. As práticas vinculadas à sua aferição criam constructos que levam implícitas limitações no que diz respeito à apreensão da realidade. A mesma é reduzida a variáveis categorizáveis e quantificáveis adequadas a trilhas de causalidade que se ajustam a modelos matemáticos. Ademais, desta perspectiva unilateral (a visão dos atores envolvidos é omitida), a investigação sobre a origem e a distribuição da AIDS reproduz o discurso sobre "o outro" salientando os aspectos que colocam o pesquisador e os meios de comunicação em posições mais distantes das pessoas que sofrem a doença, tornando-as absolutamente estranhas. Isto pode ter uma repercussão na construção que fazem da doença os destinatários da informação. Por último, à medida que o risco comportamental é reduzido a aspectos observáveis, e às vezes quantificáveis da conduta, enfatiza-se a necessidade de controle individual, social e moral.

A exposição ao risco implica sempre um componente de atos volitivos, isto é, condutas que envolvem a vontade. As limitações antes descritas se magnificam quando se trata de abordar o comportamento no plano explicativo causal sem reparar no sentido dos atos e no contexto em que estes se dão. Alguns autores postulam que a percepção e valorização individual de um risco faz-se mediante a avaliação subjetiva dele em relação à totalidade dos perigos do cotidiano (Hayes, 1992; Kendall, 1993). A avaliação do risco deve levar em coma aspectos contextuais do cotidiano do adolescente que vive no Rio de Janeiro, não podendo deixar de registrar o convívio permanente com a violência e epidemias em cuja gênese influi a desigualdade estrutural, aparentemente agravada pelo advento da recessão econômica.
Além da informação sobre a AIDS, outro fato marcante foi a diferença observada entre os sexos, tendo os estudantes do sexo masculino melhor nível de conhecimento, uma atitude de maior preocupação e alerta, além de uma aparente posse da iniciativa e do controle. Podemos atribuir estas observações às características próprias da construção cultural de papéis diferenciais de gênero. Parker (1991) destaca como a construção da sexualidade e seus papéis, no Brasil, passa pela superposição de vários discursos, dos quais o mais tradicional se baseia na atribuição de um caráter passivo à mulher. Na nossa pesquisa ficou patente o menor poder de negociação de estratégias de prevenção da AIDS entre as adolescentes. Concordamos com Paiva (1994) quanto à necessidade de se proporcionar uma visão contextualizada das decisões sobre atividade sexual. Noções de responsabilidade e autonomia não podem ser cobradas da mulher latino-americana sem considerar a tradição patriarcal da ideologia de gênero, a religião, e a influência modernizante do higienismo e da sexologia, além da própria construção cultural da ideologia erótica.

Torna-se evidente a necessidade de implementação e aprimoramento da educação sexual nas escolas face ao despreparo dos jovens para a vivência da sexualidade com menos risco. Já em 1981, ainda antes do começo da crise gerada pela AIDS, setores da sociedade norte-americana lutavam pela elaboração de um curriculum de educação sexual alertando sobre a precariedade da prática nos Estados Unidos (Penland, 1981; Scales, 1981). A AIDS viria a evidenciar esta carência (Cleary, 1991). As práticas de educação sexual institucionalizada constituem um desafio para se refletir sobre a teoria - nos seus aspectos filosófico e ético. As metodologias educativas racionalistas implementadas no nível individual, buscando promover um "modo de vida saudável", esbarram na ausência de contextualização. Assim, esquece-se de que a percepção do risco para a saúde é claramente influenciada pelos papéis culturais designados segundo grupos de idade (Backett \& Davison, 1992), gênero, e em determinados marcos sócio-culturais.

No que diz respeito à construção simbólica da AIDS por pane dos adolescentes pobres do Rio de Janeiro, revela-se a existência de vários discursos que se superpõem, refletindo traços 
do campo mais amplo da representação cultural da doença no Brasil. As principais imagens que se esboçam, configuram-se com relação ao corpo enquanto espaço de investimento simbólico. A mais notável das metáforas, a de "limpeza" e "sujeira", está presente também em outras situações do cotidiano dos informantes em que explicações essencialistas reduzem os fenômenos à natureza idiossincrásica das pessoas ("ele é limpeza" ou "o cara é sujeira"). Também se refere ao fato de ser ou não flagrado na transgressão de determinado código ("pintou sujeira" ou "pintou limpeza"). Outros termos utilizados têm o mesmo valor semântico, e.g., "lama", "meleca". Com relação à AIDS como sujeira, o locus da representação é o próprio corpo, onde se colocam as ansiedades e dúvidas, e em cuja superfície buscam-se os sinais para proteger-se do mal. Estas representações aproximam-se das concepções de "pureza" contraposta às "crenças-perigo" ou de "poluição", presentes em praticamente todas as culturas (Douglas, 1976). Elas constituem estruturadores da percepção das noções antagônicas de ordem-desordem, formação forma, vida-morte. As imagens de invasão ou de corrupção do que antes era limpo e aproximam-se da metáfora pré-romântica da conspurcação como protótipo da representação da lepra, com a conotação de algo que macula, corrompe ou suja (Sontag, 1989). Na história das epidemias, há um paralelo evidente com as interpretacões pré-causais referidas ao corpo que evocam representações de horripilância, tortura e usurpação do mesmo (Herzlich \& Pierret, 1984). Do ponto de vista de atribuição de causalidade, elas provavelmente se perpetuam como uma representação diacronicamente anterior (a contaminação, a poluição por miasmas) à qual se superpõem formas novas de se ver a doença à luz da teoria dos germes e do contágio.

Também se delineia no imaginário dos jovens, referida ao corpo, uma segunda metáfora da apropriação, controle e destruição por forças poderosas: a morte sob a forma de uma mulher de programa, o Estado que esconde a verdadeira magnitude de uma epidemia, o laboratório que cria um vírus, os estrangeiros de costumes diferentes, os homossexuais cruéis. Vários outros povos têm atribuído as epidemias aos seus vizinhos, constituindo-se assim a representação da "doença dos outros", que se desdobra na atribuição do estado de portador como rótulo para as minorias e imigrantes pobres e refugiados na Europa e nos Estados Unidos (Weeks, 1985; Altman, 1986; Treichler, 1991, 1992).

A desconfiança na informação oficial é um fenômeno já conhecido de outras epidemias (Pollak et al., 1989). O discurso do adolescente pobre do Rio de Janeiro parece apresentar, todavia, uma especificidade a este respeito. Ele não está repetindo a paranóia política do Primeiro Mundo. A sensação de usurpação e controle externo pode representar a realidade dos excluídos de uma sociedade extremamente desigual. Também revelam-se não só o descrédito institucional, como a sensação que têm os adolescentes pobres de não fazerem parte ativa da vida do país e de serem elementos descartáveis da sociedade. Frente a uma realidade ameaçadora, não há nenhum discurso que reconheça a sua existência, os seus direitos e sua dignidade. Na ausência de uma voz que lhes confira poder ou que demonstre o desejo de incluí-los na sociedade, esta população fica relegada aos interstícios da coletividade, às partes mais frouxas de um tecido social de estrutura congenitamente precária.

Os depoimentos dos alunos mostram as dificuldades que podem ser esperadas em um período em que o corpo se desenvolve somaticamente, em que se magnifica sua dimensão de suporte simbólico, de locus de construção do "eu", de reificação de uma identidade. É concebível que as representações de saúde e doença, assim como as de sexualidade e identidade, venham a ser estruturadas de acordo com o repertório de símbolos oferecido pela cultura. A pesquisa sobre o risco de AIDS deveria reconhecer essa construção cultural (Vance, 1991). Por isso, é necessária uma abordagem teórica que se afaste da ótica individualizante, essencialista e particularista da psicologia e da medicina, para reconhecer o caráter de realidade subjetiva construída da identidade. Não é possível prescindir dá importância das relações sociais e dos papéis designados pela cultura aos atores na construção da identidade (Schutz \& Luckmann, 1973; Berger \& Luckmann, 1973; Goffman, 1975; Camilleri et al., 1990). Para alguns pesquisadores, a construção da identidade é um passo 
prévio ao fato do assumir uma consciência que possibilita qualquer resposta política ou participação comunitária. Weeks (1985), entre outros autores, propõe ir além dos fatores biológicos e psicológicos no processo de construção de uma identidade e na estruturação de um "eu" multidimensional através da ação do "self", o ser humano como sujeito e objeto social de sua própria ação. Entre as dimensões desta identidade construída estão a política (o "eu-cidadão") e a sexual (o "eu sexual") em conexão íntima com a construção do gênero. Por isso, ao investigar comportamentos, há que se buscar os significados das práticas, os quais são investidos de valores. Também não são fenômenos objetivos, e sim portadores de importantes relações de poder decorrentes de vários fatores, dentre eles, a estrutura sócioeconômica e a própria construção cultural. Neste sentido, a metáfora da usurpação do corpo, observada nos nossos adolescentes, revelaria um desejo de sobrepujar a impotência frente à situação: de resistir ao controle e à exclusão ditados pelos discursos hegemônicos. Este desejo seria acompanhado de práticas de transgressão aparentemente incompreensíveis para o resto da sociedade, como o baile "funk" violento, a pichação, a prática do "surf" ferroviário e os "arrastões" nas praias. Nelas, o corpo, antes objeto de controle e castigo, passa a ser sujeito de práticas de revolta e resistência, subvertendo o uso do espaço público.

Uma terceira representação se refere ao castigo, visto também em relação ao corpo. Por vezes apresenta-se de forma velada, quando se culpabiliza ou responsabiliza vagamente alguém pela presença da AIDS no Brasil e, mais explicitamente, quando se atribui diretamente a epidemia aos costumes (mores) de certas pessoas. Pega-se AIDS por andar com pessoas erradas. Esta construção dá continuidade a um discurso que culpabiliza as vítimas, como ocorreu no início da epidemia de AIDS.

Um outro aspecto a ser abordado a partir da pesquisa do conteúdo simbólico do discurso da AIDS dos adolescentes é a figura do malandro em desgraça, que emerge como alternativa ao estereótipo tradicional e local do "esperto". Esta categoria de "malandragem", que poderia ser encarada como um indicador de "desvio", está longe de ser um conceito claro e preciso, já que, como foi atestado pelos depoimentos, a sua definição se dá de uma forma por vezes contraditória ou. mais frequientemente, ambivalente. É evidente que, frente à violência crescente, a cultura do "malandro" sofre o impacto, existindo uma tendência à negação ou à reformulação. Ainda assim, vê-se que, ao mesmo tempo em que se tenta fugir da ambigüidade, mantém-se, no entanto, a possibilidade de entrar no interstício, no desvio, mediante a transgressão de regras estabelecidas. Embora neguem-se as condições tidas como desvio ("bandido", homossexual), existem menos barreiras e interdições do que pontes e possibilidades de contato entre categorias cujo contato se supõe proibido. Estas possibilidades de desvio recolocam as categorias tidas como antagônicas. Assim, a relação dicotômica mais simples de sexo biológico (Homem $\mathrm{X} \mathrm{Mu}$ lher) passa a incluir, por analogia, relações de preferência ou opção, e de poder, graças a esse espaço intersticial de contato. Desta perspectiva, a relação passa a ser vista como: [Homem $=$ garanhão $=$ ativo $=$ predador $=$ malandro $=$ quem come] vs. [Não homem (mulher, bicha) $=$ fraco $=$ passivo $=$ presa $=$ otário $=$ quem não come ou é comido]. Nessa visão mais tradicional, o adolescente do Rio de Janeiro se debate entre pegar AIDS por ser "malandro" ou "otário". A percepção da transgressão como algo possível vai além da perspectiva instrumental e utilitária que vê a delinqüência como meio de sobrevivência ou da malandragem como simples forma de auto-afirmação regional. Entre as peculiaridades da cultura brasileira, Parker (1991) atribui à transgressão um papel importante na forma como se articulam os discursos simultâneos e conflitantes da sexualidade neste país.

Para finalizar, resta-nos observar as atitudes dos adultos (professores e monitores). Esta visão é importante já que seu discurso se traduz em práticas institucionalizadas que se convertem em fins em si mesmos. Expressou-se lástima e piedade em algumas ocasiões, desprezo e preconceito em outras. Estas atitudes podem manifestar não só inconsistência nos discursos de indivíduos como também contradições inerentes à própria estrutura do sistema brasileiro de assistência ao menor. Sendo historicamente constituído por duas entidades, a Funabem e a 
Legião Brasileira de Assistência (LBA), herdaram das instituições de "caridade" um modelo paternalista de assistência em que o Estado somente reconhece o mérito da assistência através da atribuição de carência e necessidade. Novas demandas, como o problema da violência, devem ser atendidas pelo aparelho estatal sob a forma de ações compensatórias, evidenciando que uma política de laissez faire seria incapaz de contornar os problemas gerados pela estrutura e o mercado. As práticas particularistas e imediatistas revelam não só a incapacidade de prevenir os problemas, mas também a restrição ao reconhecimento da cidadania que permeia estas práticas, uma vez que há um deslocamento do "direito de cidadão" para o "mérito da necessidade" que se torna critério de programa (Bierrenbach, 1982; Fleury, 1989; Sposati, 1989). Neste cenário, a solidariedade está longe de ser uma categoria de apoio entre iguais; seus agentes na sociedade devem provir de uma instância diferente a um Estado de interesses privatizados ou sua ação leva implícita a reforma desse tipo de Estado.

\section{CONCLUSÃO}

Este estudo se limita a entrevistas feitas com voluntários em um ambiente institucional. As conclusões não podem ser generalizáveis e representam, no máximo, apreciações da população de adolescentes de baixa renda das favelas da Zona Norte do Rio de Janeiro e da Baixada Fluminense, estando, talvez, sobre-representado, um segmento de pessoas que alguma vez morou na rua e que se beneficiou dos aparelhos estatais de proteção à infância.

Quanto ao conhecimento sobre AIDS, vê-se que ele é fragmentário e inconsistente. Embora não tenha sido feita uma pesquisa sistemática do material veiculado, pode-se inferir que há ambigüidade e falta de ponderação nos conteúdos. De qualquer forma, fica patente a falta de uma campanha educativa abrangente, clara e significante em termos da cultura brasileira através da qual o adolescente possa superar as dificuldades de perceber-se como uma pessoa em risco. Também se deve fornecer os meios práticos de prevenção. Antes de implementar ações de educação sexual, como parte de práticas mais abrangentes de educa- ção em saúde, deve-se munir os professores com informações relevantes e métodos de ensino, levando em conta dificuldades envolvidas quando se fala de sexualidade.

A percepção dos perigos para a saúde, decorrentes da vivência da sexualidade e do uso de substâncias, exige um redimensionamento da própria noção técnica de risco. Ela deve objetivar, não o risco, mas os riscos, pois são objetos mais totais e complexos e, desvelá-los, requer um esforço interdisciplinar. O objetivo desta tarefa deve ser a qualidade de vida, a felicidade e a segurança de indivíduos e coletivos e não aspectos pontuais e particulares dos recortes institucionais da prática da saúde pública. O risco reduzido e quantificado deve ser revisto e interpretado em termos qualitativos, isto é, estabelecer o nexo com outros fatores de fragilização (violência e recessão). Em suma, nossa visão contrapõe-se à do higienismo individualista contemporâneo propondo pensar o "risco relativizado" de coletivos vulneráveis, em vez do "risco relativo" da Epidemiologia.

No que diz respeito às representações simbólicas sobre a AIDS, o discurso do adolescente pobre do Rio de Janeiro não é uniforme e incorpora falas segmentares. A visão predominante que se tem da AIDS é a do "castigo injusto" em que a vítima é inocente. Este discurso leva o oprimido a um reencontro consigo mesmo, podendo representar uma tentativa de organização com base em uma identidade dificilmente construída. Ele contempla o prazer e a violência de baixo para cima, como subvertores de uma desordem estrutural; muda o uso do espaço público, libera paixões e negocia prazeres. Esta representação difere daquela do "castigo justo", por maldade ou pecado, discurso propalado por prelados da Igreja Católica do Brasil no começo da epidemia e que ainda permeia os posicionamentos da hierarquia eclesiástica frente às campanhas de controle da AIDS. Este discurso, embora não muito freqüente, quando incorporado pelo adolescente pobre identifica o oprimido "culpado" com o opressor, em forma análoga à "gestão repressiva" da AIDS identificada por Pollak et al. (1989).

Quando se pensa em proporcionar uma resposta a esta realidade, concordamos com Patton (1990), à medida que há um imperativo de 
redimensionar os símbolos que fazem parte da linguagem da AIDS como novo ponto de partida para um controle nascido da comunidade. A negação de identidade ou a identificação dos oprimidos com figuras de poder, traz implícita a impossibilidade de organização. A construção de uma identidade pode gerar organização "resistência" e restabelecer a relação de linguagem e poder em outros patamares. Assim, um primeiro passo para um controle mais realista e efetivo da AIDS deve ser o reconhecimento da construção simbólica da realidade pelo adolescente que é indissolúvel do seu contexto. Este reconhecimento torna o adolescente sujeito histórico não-objeto de mudança. Isto significa que a compreensão da influência do comportamento sexual ou de qualquer variável comportamental que incida sobre a saúde, precisa de uma abordagem que não se restrinja aos seus aspectos biológicos e que inclua a forma como se produzem a construção cultural e social dos seus fatores correlatos. Assim, no campo da sexualidade, o comportamento é inseparável da construção da masculinidade, feminilidade, papéis, afetividade e segurança. Por isso as ações de promoção de saúde não podem ser implementadas universalmente. Um segundo passo, não como mais uma alternativa senão como ação complementar a esta abordagem construcionista reside no fato de que a Sociedade Civil e o Estado precisam reconhecer integralmente os direitos do adolescente enquanto cidadão. Qualquer posicionamento teórico e prático sobre o papel do corpo na estrutura social passa pelo seu valor simbólico e pelo questionamento da própria estrutura que determina as condições de vida. A legitimação da cidadania não deveria depender da vivência do desastre de uma epidemia como já aconteceu com outras comunidades (Altman, 1986, 1988). Até agora as ações orientadas ao controle da AIDS, baseiam-se nas pesquisas que reduzem os seus objetos à esfera psicológica individualizante, seguindo uma lógica puramente instrumental que nega a subjetividade. Caplan \& Nelson (1973) já alertavam para as consequiências da limitação deste tipo de pesquisa (person-centered) quando se trata, em realidade, de problemas sociais. A atribuição causal que se faz de maneira enviesada a distúrbios psicológicos individuais so- mente colabora para legitimar a culpabilização das próprias vítimas.

Cremos na importância da construção da realidade por meio de signifîcados culturais e papéis simbólicos a serem colocados em cena através da interação social. Alguns fenômenos, como a intencionalidade dos atos e a identidade, passam a ser encarados pelo sentido que a pessoa confere aos seus comportamentos em relação aos atos e intenções dos outros. A partir desta abordagem, o trabalho (as ações de resposta) devem passar pela recriação e problematização das relações sociais. A colocação dos fenômenos em contextos simbólicos e interacionais implica a desobjetivação dos indivíduos, isto é, eles deixam de ser objeto de pesquisa e intervenção. Também implica redimensionar as ações do Estado e conferir um novo valor às iniciativas e à participação da comunidade.

\section{AGRADECIMENTOS}

A I. H. Matida, da Divisão de DST/AIDS da Secretaria de Estado da Saúde (RJ) por sua participação na adequação dos questionários e nos contatos com as instituições. À M. Monteiro por sua participação na execução de entrevistas e no aconselhamento aos adolescentes. A C. J. de Carvalho e M. W. Guimarães do Centro Brasileiro da Criança e o Adolescente, pela autorização necessária à realização do trabalho nas escolas.

\section{RESUMO}

\section{MERCHÁN-HAMANN, E. Grau de} Informação, Atitudes e Representações Sobre o Risco e a Prevenção de AIDS em Adolescentes Pobres do Rio de Janeiro, Brasil. Cad. Saúde Públ., Rio de Janeiro, 11 (3): 463-478, jul/set, 1995.

Com o objetivo de avaliar a situação do adolescente brasileiro com respeito ao risco e prevenção ,da AIDS/HIV, foram entrevistados 416 estudantes, dentro do marco institucional-assistencial do Centro Brasileiro da Infância e Adolescência. Os adolescentes pertenciam a duas categorias institucionais: escolas abertas à comunidade 
ou instituições fechadas para menores infratores. As entrevistas semiestruturadas foram voluntárias, anônimas e sigilosas. As fontes de informação sobre AIDS/HIV mais freqüentemente identificadas foram os meios de comunicação de massa, e em particular a televisão. Os entrevistados manifestaram dúvidas e desconfiança na informação oficial mostrando uma escassa compreensão sobre certos aspectos do contágio e prevenção: quase $70 \%$ acreditam na transmissão via picada de mosquito e, em torno de $40 \%$, em formas de contágio casual como o contato direto com ferimentos, cicatrizes e com utensílios de banheiro. Houve diferenças entre as respostas dos alunos e as das alunas, sendo que os primeiros mostraram um nível de preparo melhor ao tempo que pareciam deter maior autonomia nas iniciativas referentes à sexualidade. Atitudes de segregação e exclusão de pessoas corn AIDS persistem. A falta de prevenção foi atribuída à impossibilidade de prever que os encontros sexuais iriam a ocorrer. Os aspectos simbólicos relacionados com as causas de AIDS/HIV revelaram grande variabilidade: embora a maioria veja a doença "como qualquer outra", $80 \%$ a associam com excessos na conduta sexual e $40 \%$ com comportamento homossexual. As imagens causais variam desde um ponto de vista predominante da AIDS como "castigo injusto" (algo introduzido deliberadamente por estrangeiros) a discursos menos freqüentes de culpabilização (AIDS como punição justificada por "conduta pecaminosa"). Há várias metáforas referidas ao corpo: a "sujeira" (manchas escuras, feridas, tumores); o seu deterioramento irreversível; a usurpação por forças externas mais potentes. A atitude positiva à iniciação sexual não é influenciada por cogitações sobre os riscos de doença, a possibilidade de gestação, e imperativos religiosos. Uma atitude ambígua com respeito à transgressão (estereotipada na figura do "malandro" do Rio), pode ter influência na percepção do risco e da prevenção. Analisam-se as informações coletadas à luz da interpretação dos discursos dos meios de comunicação, do estudo de outros contextos e das pesquisas sobre a especificidade da construção cultural da sexualidade no Brasil. Enfatiza-se a necessidade de implementação de ações mais claras e diretas na veiculação de informação. Também busca-se uma compreensão mais abrangente da noção de risco baseada na colocação dos fenômenos relativos ao processo saúde-doença nos seus contextos sócio-econômicos e culturais, o que pode ser útil para implementar medidas de controle culturalmente adequadas mediante $o$ redimensionamento dos símbolos da AIDS. Enfatizamos a necessidade de uma melhor compreensão dos determinantes sociais e econômicos do risco de doença, e o apoio aos discursos que conferem poder e dignidade aos adolescentes pobres por meio do reconhecimento pleno de sua cidadania.

Palavras-Chave: AIDS; Adolescente; Atitudes; Percepções

\section{REFERËNCIAS BIBLIOGRAFICAS}

ALTMAN, D., 1986. AIDS in the Mind of America. New York: Anchor Press - Doubleday.

1988. Legitimation through disaster: AIDS and the gay movement. In: AIDS, The Burdens of History (E. Fee \& D. M. Fox, eds.), pp. 301-315, Berkeley: University of California Press.

BACKETT, K. \& DAVISON, C. 1992. Rational or reasonable? Perceptions of health at different stages of life. Health Education Journal, 51: 55-59.

BERGER, P. L. \& LUCKMANN, T., 1973. A Construção Social da Realidade. Petrópolis: Vozes.

BIERRENBACH, M. I. R. S, 1982. Política e Planejamento Social - Brasil: 1956-1978. São Paulo: Cortez.

CAPLAN, N. \& NELSON, S. D., 1973. The nature and consequences of psychological research on social problems. American Psychologist, 3: 199-211.

CAMILLERI, C.; KASTERSZTEIN, J.; LIPIANSKY, E. M.; MALEWSKA-PEYRE, H.; TABOADA-LEONETTI, I. \& VASQUEZ, A., 1990. Stratégies Identitaires. Paris: Presses Universitaires de France.

CLEARY, M. J., 1991. School health education and a national Curriculum: one disconcerting scenario. Journal of School Health, 61: 355-358. 
DICLEMENTE, R. J.; ZORN, J. \& TEMOSHOK, L., 1987. Adolescents' knowledge of AIDS near AIDS epicenter. American Journal of.Public Health, 77: 876-877.

DOUGLAS, M., 1976. Pureza e Perigo. São Paulo: Perspectiva.

FLEURY, S. M. T, 1989. Assistência na previdência social: Uma política marginal. In: Os Direitos (dos Desassistidos) Sociais (A. Sposati; M. C. Falcão \& S. M. T. Fleury, orgs.), pp. 31-108, São Paulo: Cortez.

GOFFMAN, E., 1975. A Representação do Eu na Vida Cotidiana. Petrópolis: Vozes.

HAYES, M. V., 1992. On the epistemology of risk: language, logic and social science. Social Sciences and Medicine, 35: 401-407.

HERZLICH. C. \& PIERRET, J., 1984. Malades d'Hier, Malades d'Aujourd'hui: de la Mort Collective au Devoir de Guirison. Paris: Payot.

1992. Uma doença no espaço público: A AIDS em seis jornais franceses. Physis, Revista de Saúde Coletiva, 1: 7-35.

KENDALL, C., 1993. The Construction of Risk in AIDS Control Programs: Theoretical Bases and Popular Responses. Trabalho apresentado na Conferência sobre Perspectivas Internacionais em Pesquisa sobre Sexualidade (ARHN Working Group on Sexual Behavior Research), Rio de Janeiro, 22-25 Abril. (Mimeo.)

MANN, J.; TARANTOLA, D. J. M. \& NETTER, T. W. (Orgs.), 1993. A AIDS no Mundo. Rio de Janeiro: ABIA/IMS-UERJ/Relume-Dumará.

MILLER, H. G.; TURNER, C. F. \& MOSES, L. E. (Eds.), 1990. Committee on AIDS Research and the behavioral, social and statistical sciences; Comission on the behavioral and social sciences and education; National research council. AIDS, The Second Decade. Washington: National Academy Press.

MOATTI, J-P.; DAB, W. \& POLLAK, M., 1992. Les Français et le Sida: les comportements évoluent. La Recherche, 247: 1202-1211.

PAIVA, V., 1994. Sexualidade e gênero num trabalho com adolescentes para prevenção do HIV/AIDS. In: A AIDS no Brasil (R. Parker; C. Bastos; J. Galvão \& J. S. Pedrosa, orgs.), pp. 231-250, Rio de Janeiro: ABIA/IMS-UERJ/Relume-Dumará.

PARKER, R.G., 1991. Bodies Pleasures and Passions: Sexual Culture in Contemporary Brazil. Boston: Beacon Press.

1994. A Construção da Solidariedade: AIDS, Sexualidade e Política no Brasil. Rio de Janeiro: ABIA/IMS-UERJ/Relume-Dumará.
PATTON, C., 1990. Inventing AIDS. New York: Routledge, Chapman and Hall.

PENLAND, L. R., 1981. Sex education in 1900, 1940 and 1980: an historical sketch. The Journal of School Health, 51: 305-309.

POLLAK, M., 1990. Os Homossexuais e a AIDS: Sociologia de uma Epidemia. São Paulo:. Estação Liberdade.

POLLAK, M.; DAB, W. \& MOATTI, J-P., 1989. Systèmes de reaction au SIDA et action préventive. Sciences Sociales et Santé, 7: 111-140.

RODRIGUES, J. C., 1979. O Tabu do Corpo. Rio de Janeiro: Achiamé.

SCALES, P., 1981. The new opposition to sex education: a powerful threat to a democratic society. The Journal of School Health, 51: 300-304.

SCHUTZ, A. \& LUCKMANN, T., 1973. Las estructuras del Mundo de la Vida. Buenos Aires: Amorrortu.

SONTAG, S., 1989. AIDS e Suas Metáforas. São Paulo: Companhia das Letras.

SPOSATI, A., 1989. A assistência social e a trivialização dos padrões de reprodução social. In: Os Direitos (dos Desassistidos) Sociais (A. Sposati; M. C. Falcão \& S. M. T. Fleury, orgs.), pp. 530, São Paulo: Cortez.

TREICHLER, P. A., 1991. AIDS and HIV infection in the Third World: A First World chronicle. In: AIDS, the Making of a Chronic Disease (E. Fee \& D. M. Fox, eds.), pp. 377-412, Berkeley: University of California Press.

1992. Social history and representations. AIDS, HIV, and the cultural construction of reality. In: The Time of AIDS: Social Analysis, Theory, and Method (G. Herdt \& S. Lindenbaum, eds.), pp. 65-98, Newbury Park: Sage Publications.

VALlinOTO, T. C., 1991. A Construção da Solidariedade: Um Estudo sobre a Resposta Coletiva à AIDS. Tese de Mestrado, Rio de Janeiro: Escola Nacional de Saúde Pública, Fundação Oswaldo Cruz.

VANCE, C., 1991. Anthropology rediscovers sexuality: a theoretical comment. Social Science and Medicine, 33: 875-884.

WATNEY, S., 1989. Policing Desire: Pornography, AIDS and the Media. Minneapolis: University of Minnesota Press.

WEEKS, J., 1985. Sexuality and its Discontents. Meanings, Myths and Modern Sexualities. London: Routledge \& Kegan. 